\title{
Apoptosis in the Dorsal Lateral Geniculate Nucleus after Monocular Deprivation Involves Glutamate Signaling, NO Production, and PARP Activation
}

\author{
Carlo Nucci,* Silvia Piccirilli,† Paola Rodinò,† Robert Nisticò,† Marina Grandinetti,‡ \\ Luciano Cerulli,* Marcel Leist,§ Pierluigi Nicotera,§ and Giacinto Bagetta†'† \\ *Department of Biopathology, Chair of Physiopathological Optics, University of Rome "T or Vergata", Via O. Raimondo, \\ 00173 Rome, I taly; †"Mondino-Tor Vergata" Center for Experimental Neurobiol ogy, University of Rome "T or Vergata", \\ Via della Ricerca Scientifica, 00133 Rome, I taly; łDepartment of Pharmacobiology, University of Calabria, \\ 87036 Arcavacata di Rende Cosenza, I taly; and §Department of Mol ecular Toxicology, \\ Faculty of Biology, University of Konstanz, D-78457 Konstanz, Germany
}

In mammals, visual experience during early postnatal life is critical for normal development of the visual system. Here we report that monocular deprivation for 2,7 , and 14 consecutive days causes p53 accumulation, cell death, and progressive loss of neurones in the dorsal lateral geniculate nucleus (dLGN) of newborn rats and these are prevented by NMDA and non-NMDA glutamate receptor antagonists, and by L-NAME, an inhibitor of nitric oxide synthesis. Monocular deprivation also increases dLGN levels of citrulline, the coproduct of nitric oxide synthesis, and this, as well as cell death and neuronal loss, is abolished by antagonists of glutamate receptors and by L-NAME. Finally, poly-(ADP-ribose) polymerase (PARP) knock-out mice appear to be protected from monocular deprivationinduced cell death. In conclusion, during early postnatal development of the rat visual system monocular deprivation causes excitotoxic, nitric oxide-mediated, cell death in the dLGN that appears to be apoptotic and also requires activation of PARP. $\odot 2000$ Academic Press

Key Words: rat; nitric oxide; N-methyl-D-aspartate receptors (NMDA); non-NMDA receptors; poly-(ADPribose) polymerase.

Visual experience during early postnatal life is essential for the normal development of the vertebrate visual system. Transient monocular deprivation of visual input (MD) during this period causes a progressive decline in the number of visual cortical cells which respond to stimulation of the affected eye. Then, visual performance strongly diminishes and the eye becomes amblyopic (1-3). This correlates with a reduction of the cortical territories receiving inputs from the dorsal lat- eral geniculate nucleus (dLGN), which are functionally connected with the deprived eye, and it causes a substantial degree of shrinkage of affected dLGN cells (1-3). One possible explanation for these findings is that functional changes in the visual system may be the consequence of neuronal death in the corresponding areas of the deprived LGN. Here we report that monocular deprivation for 2,7 , or 14 consecutive days in neonatal rats caused p53 accumulation, cell death, and a progressive loss of neurones in this relay of the visual pathways. In these areas early accumulation of citrulline, the coproduct of nitric oxide (NO) synthesis (4) suggested an activation of NO synthase. Systemic administration of either glutamate receptor antagonists, or inhibitors of nitric oxide synthase abolished accumulation of citrulline, and prevented neuronal loss in the dLGN. In addition, the effects of MD were examined in wild-type and poly-(ADP-ribose)-polymerase (PARP)-deficient mice. These experiments showed that in the dLGN PARP is necessary for MD-triggered cell death that appears to be of the apoptotic type. Altogether, these findings show that MD causes cell death in the dLGN, by activating glutamate signaling and excessive NO production, with activated PARP being required for neuronal death.

\section{METHODS}

Animals. Newborn Long Evans rat pups ( $20 \pm 3 \mathrm{~g}$ at $4-5$ days of age) were obtained from MORINI (San Polo D'Enza, RE, Italy), housed in a temperature-controlled $\left(20 \pm 2^{\circ} \mathrm{C}\right)$ and humiditycontrolled (60\%) animal room under $12 \mathrm{~h}$ light/12 h dark cycles. Water and food were available ad libitum. PARP -/- mice (C57B1/ $6 \times 129$ background) were generated and donated by Z. Q. Wang (IARC, Lyons, France) (5). They were crossed back to C57B 1/6 wildtype (wt) mice through 2 cycles of heterozygous matings, and for the 
experiments 14-day-old wt or -/- offspring pups were used after typing by PCR.

Treatment schedule. At day 14 post-partum, the right eye of rats or mice ( $n=6$ per group) was closed by suturing the eyelids for 2,7 , or 14 days. Age-matched nonsutured animals ( $n=6$ per group) were used as control. The surgical procedure was carried out under ether anesthesia. For the pharmacological intervention studies, rats received intraperitoneal (i.p.) injections of $\mathrm{N}^{\omega}$-nitro-L-arginine methyl ester (L-NAME) or D-NAME ( $3 \mathrm{mg} \mathrm{kg}^{-1}$ given twice daily during the whole period of MD) (Sigma, Milan, Italy). Alternatively, rats received daily i.p. injections of (R, E) 2-amino-4-methyl-5-phosphono-3-pentenoic acid (CGP040116) (CIBA-GEIGY, Basel, Switzerland) $\left(7 \mathrm{mg} \mathrm{kg}^{-1}\right)$ or MK $801\left(0.3 \mathrm{mg} \mathrm{kg}^{-1}\right)$ or GYKI52466 (3.3 $\mathrm{mg} \mathrm{kg}^{-1}$ ) (RBI, Natick, MA). The experimental protocol and procedures used meet the guidelines of the EU (European Council Directive 86/609/EEC) and the Italian Ministry of Health (G.U. $n^{\circ} 40$, February 18, 1992) and have been approved by the Animal Care Committee (University of Rome "Tor Vergata").

Neuropathology. In preliminary experiments, the extension of the dLGN in the brain of newborn, Long Evans rats ( $n=6$ per group) was assessed using horseradish peroxidase tracer (6). Briefly, at eye opening (postnatal day 14) the right eyelids were sutured for 2, 7, and 14 days. Age-matched nondeprived animals were used for control. Forty-eight hours before the end of the MD-period, horseradish peroxidase ( $30 \%$ in double-distilled $\mathrm{H}_{2} \mathrm{O}$ ) was injected by a glass micropipet in to the right eye under chloral hydrate anesthesia (400 mg kg ${ }^{-1}$ i.p.); $48 \mathrm{~h}$ later, rats were deeply anesthetized with chloral hydrate and perfused transcardially with $100 \mathrm{ml}$ of saline $(0.9 \%)$ solution immediately followed by a solution of $1 \%$ formaldehyde and $2.5 \%$ glutaraldehyde in $0.1 \mathrm{M}$ phosphate buffer $(\mathrm{pH} 7.4)$ The brains were postfixed for $4 \mathrm{~h}$ at $4^{\circ} \mathrm{C}$ in the same solution. Coronal sections $(30 \mu \mathrm{m})$ were cut by a vibratome and the dLGN extension was revealed by coloring the anterogradely transported horseradish peroxidase with tetramethyl-benzidine. Sections were observed under light microscopy (Nikon, Optiphot-2). For neuropathology studies, at the end of the period of deprivation the animals were anaesthetized with chloral hydrate ( $400 \mathrm{mg} \mathrm{kg}^{-1}$ i.p.) and perfused through the left ventricle of the heart with $50 \mathrm{ml}$ of heparinized phosphatebuffered ( $\mathrm{pH}$ 7.4) saline followed by $50 \mathrm{ml}$ of $4 \%$ paraformaldehyde in phosphate-buffered saline. Two hours after the perfusion procedure had been completed, the brain was removed from the skull and postfixed in $4 \%$ paraformaldehyde for $72 \mathrm{~h}$. Serial brain coronal sections $(15 \mu \mathrm{m})$ were cut from wax-embedded tissue blocks. After randomly selecting the first section, every third section was deparaffinized and processed for in situ detection of DNA fragmentation according to the terminal deoxynucleotidyl transferase (TdT)mediated dUTP-biotin nick end-labeling (TUNEL) technique (7); morphological characteristics were also assessed in adjacent brain tissue sections $(15 \mu \mathrm{m})$ under high magnification $(100 \times)$ light microscopy using hematoxylin and eosin staining. TUNEL-positive cells were counted under light microscopy (100× magnification) in the dLGN of either side of the brain (about 4- 6 sections per brain $\mathrm{n}=6$ animals per group) and expressed as mean \pm SEM. In brain tissue sections stained with haematoxylin and eosin, the number of viable cells was counted (100× magnification) in single volumes of the dLGN of either side by applying the optical dissector technique (see 8). Accordingly, we counted the number of cells that come into focus within a counting area, as the focal plane was moved from the upper to the lower plane. Because counting should be performed when cells first come into focus, those in focus at the uppermost level were never counted. This method has been reported to avoid overestimates of numerical density and to garantee an equal chance of being sampled at all parts of the anatomical region under study (8). In fact, a random section immediately rostral to the dLGN profile was sel ected by using a random number table and every third section encountered thereafter containing the dLGN was selected for study (about $4-8$ sections per brain, $\mathrm{n}=6$ animals per group). In each sections, the dLGN area was localized using a corresponding brain section stained for horseradish peroxidase detection. Within the
dLGN, cell counting was performed in 8, randomly selected areas of $400 \mu \mathrm{m}^{2}$ by using a counting frame (M odel NE 11A, Nikon) applied to the ocular of the microscope. All profiles entirely within or intercepting one of the right-angled edges were counted as the microscope was focused. The counting area was multiplied by the distance between the first and last optical section plane $(13 \mu \mathrm{m})$ in order to obtain the volume studied. The resulting means \pm SEM from MD rats and age-matched controls were evaluated statistically for differences, using the Student $t$ test.

I mmunohistochemistry for p53, glial fibrillary acid protein (GFAP) and OX-42. Two hours after the perfusion procedure had been completed (see above), the brains obtained from rats that had undergone MD for 2 or 7 days and from age-matched untreated controls ( $n=6$ per group) were removed from the skull, postfixed in $4 \%$ paraformal dehyde overnight, cryoprotected in sucrose (30\%, wt/vol), frozen in liquid nitrogen, and stored at $-80^{\circ} \mathrm{C}$ until use. Cryostat brain coronal sections, selected using a random number table, were stained by a biotin-streptavidin-amplified detection system (B-SA; BioGenex Laboratories, San Ramon, CA). After rinsing in PBS, sections were incubated with $0.01 \% \mathrm{H}_{2} \mathrm{O}_{2}$ in methanol to inactivate endogenous peroxidases; then, unspecific binding was blocked by incubating the slides with $4 \%(\mathrm{vol} / \mathrm{vol})$ normal goat serum in PBS containing $0.1 \%$ Triton $X-100$. Sections were then incubated overnight at $4^{\circ} \mathrm{C}$ with mouse anti-rat monoclonal antibodies to detect either p53 (Pab246, Santa Cruz Biotechnology, CA), or GFAP (GA-5, BioGenex, San Ramon, CA) or to detect microglial cells (OX-42; Harlan, Sera-lab, UK), all diluted 1:50 in PBS containing 4\% normal goat serum and $0.1 \%$ Triton X-100. After washing, sections were incubated successively with biotinylated goat anti-mouse immunoglobulins and horseradish peroxidase-conjugated streptavidin (BioGenex Laboratories, San Ramon, CA). Peroxidase activity was revealed using 3,3-diaminobenzidine. The specificity of the immunostaining was established routinely as previously reported (9). The number of OX-42 immunoreactive microglial cells and the number of GFAP-positive astrocytes in control and in MD animals was assessed using the optical dissector method, previously described. The number of p53 immunopositive cells were counted in the entire dLGN as described for TUNEL-positive cells.

Optic nervetransection. At postnatal day 14, the right optic nerve of MD control rats $(n=6)$ or animals that had the right eye sutured was cut with scissors at a distance of approximately $0.5 \mathrm{~mm}$ from the eye (10) under chloral hydrate (400 mg kg-1 i.p.) anesthesia. Seven days after surgery, animals were perfused as described above, and eyes and brains were removed and fixed in $4 \%$ paraformaldehyde for $72 \mathrm{~h}$. Serial coronal sections $(15 \mu \mathrm{m})$ were cut from wax-embedded tissue blocks. Every third section was processed for in situ detection of DNA fragmentation by the TUNEL technique. TUNEL-positive cells in the dLGN of either side and in the retina were counted under light microscopy ( $100 \times$ magnification). Morphological characteristics of the tissue were assessed in every other tissue section under light microscopy using hematoxylin and eosin staining.

Determination of citrulline in the lateral geniculate nucleus. MD was initiated in animals at 14 days postpartum ( $n=6$ per group) for 1 and 7 days. The levels of citrulline were determined in homogenates of LGN enriched tissue from these animals or age-matched control rats following o-phthalal dehyde (OPA) derivatization by high performance liquid chromatography as detailed el sewhere (11). The data were expressed as nmol of citrulline/g of wet tissue weight and the resulting means were evaluated statistically for differences using ANOVA followed by Tukey-Kramer multiple comparisons test.

\section{RESULTS}

\section{Monocular Deprivation Causes Apoptosis in the LGN}

MD for 2, 7, or 14 consecutive days in Long Evans newborn (postnatal day 14) rats caused the onset of 

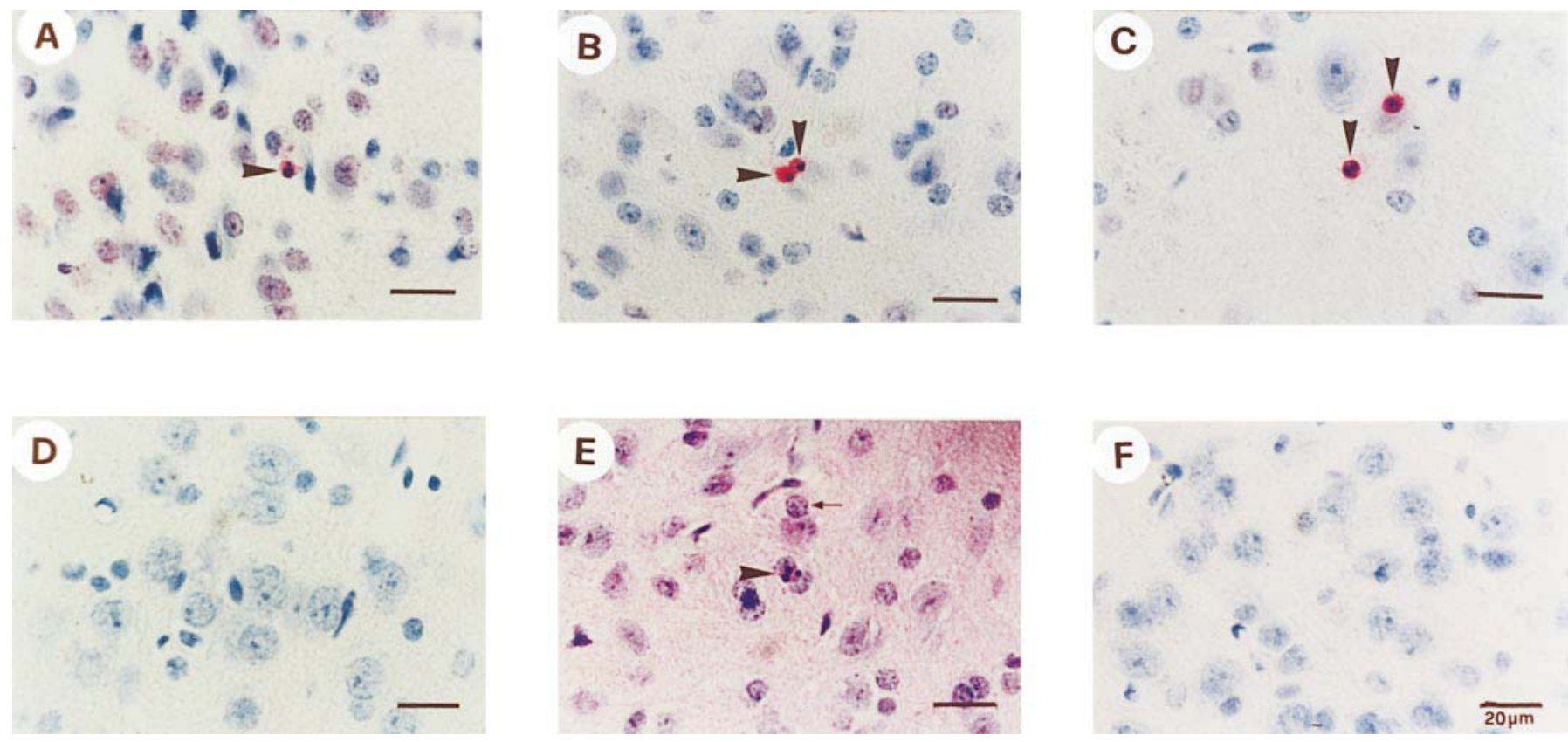

FIG. 1. Monocular deprivation (MD) induces apoptotic cell death in the dorsal lateral geniculate nucleus (dLGN) of newborn rats. In situ DNA fragmentation (TUNEL-positive cells) is evident in the dLGN of brain tissue sections obtained from rats at 2 (A), 7 (B), or 14 days (C), respectively, after the start of MD. No TUNEL-positive cells were observed in the dLGN of control rats (D). Nuclei with condensed (arrowheads) and marginalized (arrows) chromatin are apparent in an H\&E-stained section from a newborn rat after 7 days of MD (E). (F) A rat brain tissue section directly adjacent to the section in B. It was stained in the absence of TdT as negative control for the TUNEL reaction; note the lack of nuclear labeling.

DNA fragmentation (evaluated by scoring TUNELpositive cells) in the dLGN (Figs. 1A-1D), suggesting the occurrence of apoptotic cell death. The latter hypothesis was strengthened by hematoxylin and eosin staining of adjacent brain tissue sections which re vealed chromatin marginalization and nuclear condensation (Fig. 1E), typical morphological features of apoptosis (12). In addition, MD in the dLGN was accompanied by the appearance of cells that were immunopositive for the tumor suppressor protein p53, a gene product often associated with apoptosis (13) and most of these cells presented pyknotic nuclei and apoptotic bodies (Fig. 2). The number of TUNEL positive cells was significantly greater in the dLGN contralateral to the closed eye (i.e., in the dLGN, deprived of visual input signals; Table 1), and this is in accordance with the notion that in rats more than $95 \%$ of the fibers originating from the ganglion cells of one eye cross at the level of the optic chiasm. Examination of counterstained sections confirmed, in most cases, that TUNEL-labeled cell morphological characteristics are compatible with their neuronal nature. The number of elements immunoreactive for the astrocytic glial fibrillary acid protein (GFAP) (14) and OX-42, a specific marker for resting and amoeboid microglia (15), was not significantly different from that of untreated animals, indicating that MD was not associated with any reduction or activation/proliferation of astrocytes or microglial cells. These findings support the concept that MD induces death of neuronal cells in the dLGN.

The number of total viable cells in the deprived dLGN decreased as consequence of the continued apoptotic process. In haematoxylin and eosin-stained sections the number of cells per $\mathrm{mm}^{3}$ in the dLGN contralateral to the deprived eye was reduced by approximately 10,27 , and $44 \%$ after 2,7 , or 14 days of deprivation, respectively (Table 2 ).

\section{TABLE 1}

Monocular Deprivation (MD) Induces DNA Fragmentation in the Lateral Geniculate Nucleus (LGN) of Newborn Rats

\begin{tabular}{ccccc} 
Days & Control & $\begin{array}{c}\text { MD (either } \\
\text { LGN) }\end{array}$ & $\begin{array}{c}\text { MD (contralateral } \\
\text { LGN) }\end{array}$ & $\begin{array}{c}\text { MD (ipsilateral } \\
\text { LGN) }\end{array}$ \\
\hline 2 & $0.2 \pm 0.1$ & $8.5 \pm 0.3^{*}$ & $5.6 \pm 0.2^{*}$ & $3.0 \pm 0.2^{*}$ \\
7 & $0.0 \pm 0.0$ & $8.0 \pm 0.3^{*}$ & $5.2 \pm 1.3^{*}$ & $2.4 \pm 0.2^{*}$ \\
14 & $0.3 \pm 0.1$ & $8.0 \pm 1.1^{*}$ & $5.2 \pm 0.5^{*}$ & $2.5 \pm 0.2^{*}$ \\
\hline
\end{tabular}

Note TUNEL-positive cells of the LGN were scored in serial coronal brain sections $(n=6)$ from newborn rats after MD of one eye for 2,7 or 14 days or from age-matched controls ( $n=6$ per group). The total number of neurons with fragmented DNA (TUNEL-positive cells) was counted in either side of the LGN (100× magnification). The results are expressed as mean \pm SEM. Statistical differences were evaluated by using Student's t test. $* \mathrm{P}<0.01$ vs age-matched control. 

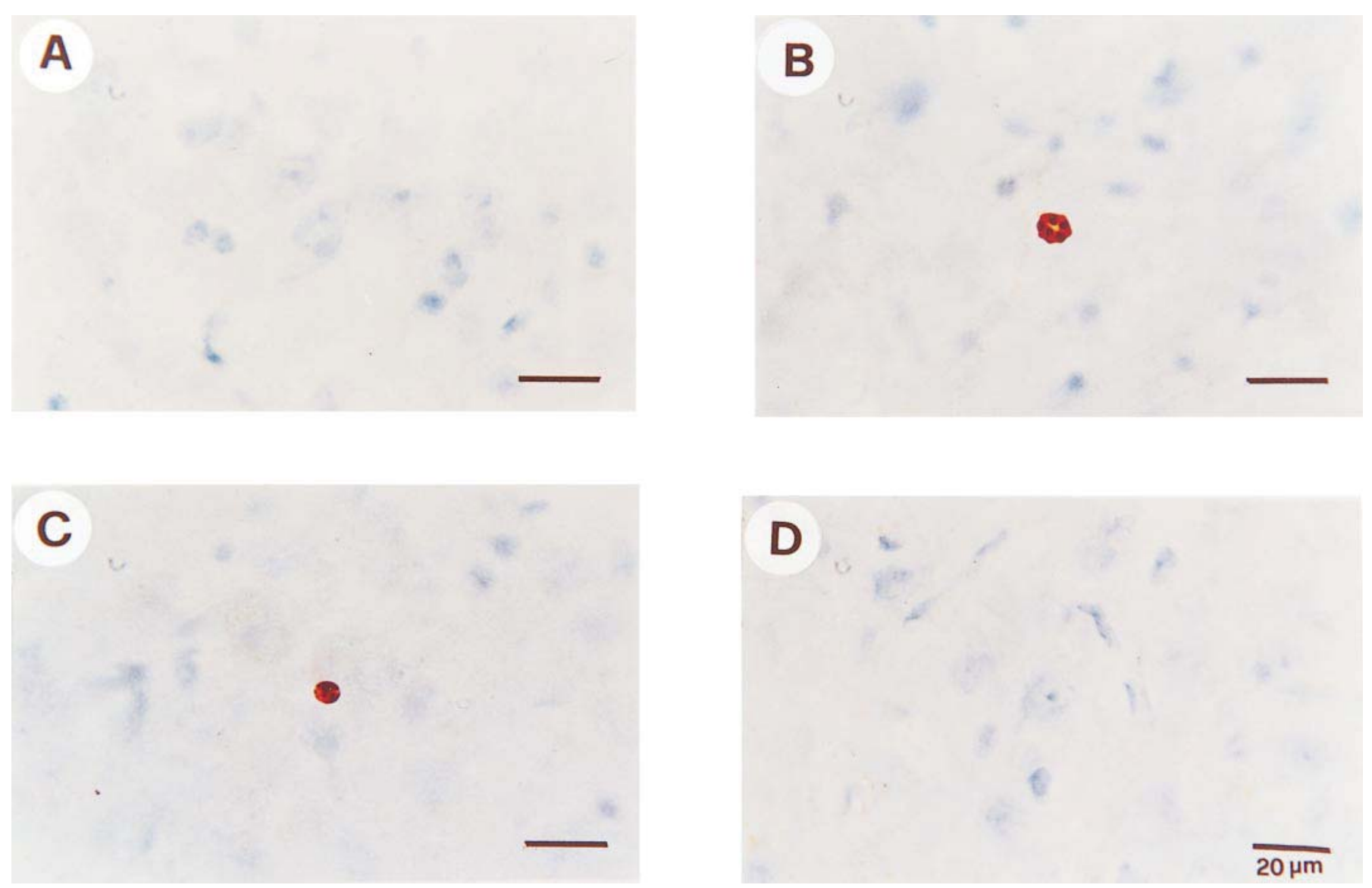

FIG. 2. Monocular deprivation induces the expression of the p53 tumor suppressor gene product in the dorsal lateral geniculate nucleus (dLGN) of newborn rats. A control brain section (A) or sections from rats that had been obtained 2 days (B) or 7 days (C) after MD were stained for p53-like immunoreactivity. (D) A rat brain section directly adjacent to the section in B stained in the absence of the primary antibody; note the lack of labeling in this negative control.

Cell death induced by MD in the dLGN seems to require the integrity of the retinogeniculate pathway. In fact, newborn rats bearing an intraorbital surgical transection of the optic nerve did not reveal any morphological sign of apoptosis in the LGN, or appearance of TUNEL positive cells after MD (Table 3). The process triggered by MD differed drastically from that observed after transection of the optic nerve: axotomy caused death of retinal cells (predominantly in the retinal ganglion cell layer) and architectural disturbance in the retina (Fig. 3), but had no effect on the dLGN ; in contrast MD had no effect on the retina even after 7 days occlusion, but caused death and cell loss in the dLGN.

TABLE 2

Monocular Deprivation (MD) Reduces the Number of Viable Cells per $\mathrm{mm}^{3}$ in the Dorsal Lateral Geniculate Nudeus (dLGN) of Newborn Rats

\begin{tabular}{cccrr}
\hline Days of treatment & Control (left dLGN) & Control (right dLGN) & MD (contralateral dLGN) & MD (ipsilateral dLGN) \\
\hline 2 & $14.5 \times 10^{4} \pm 0.8 \times 10^{4}$ & $13.8 \times 10^{4} \pm 0.8 \times 10^{4}$ & $12.9 \times 10^{4} \pm 0.8 \times 10^{4}$ & $14.5 \times 10^{4} \pm 0.7 \times 10^{4}$ \\
7 & $13.6 \times 10^{4} \pm 0.2 \times 10^{4}$ & $14.5 \times 10^{4} \pm 0.2 \times 10^{4}$ & $11.1 \times 10^{4} \pm 0.5 \times 10^{4 *}$ & $15.3 \times 10^{4} \pm 0.6 \times 10^{4}$ \\
14 & $14.5 \times 10^{4} \pm 0.4 \times 10^{4}$ & $14.6 \times 10^{4} \pm 0.4 \times 10^{4}$ & $8.5 \times 10^{4} \pm 0.4 \times 10^{4 *}$ & $15.3 \times 10^{4} \pm 0.3 \times 10^{4}$ \\
\hline
\end{tabular}

Note. Coronal brain tissue sections incorporating the dLGN were prepared from rats after MD for 2, 7, or 14 days or from age-matched controls ( $n=6$ per group) and stained with H\&E. The number of viable cells was counted using the optical dissector method (see Methods) and expressed as mean \pm SEM cells per $\mathrm{mm}^{3}$ of dLGN from 6 animals per group. Data were evaluated for statistical differences using Student's t test. * P $<0.01$ vs age-matched control (both sides) and vs ipsilateral dLGN. 
TABLE 3

Prevention of MD-Triggered Cell Death in the dLGN by Optic Nerve Transection, Treatment with Glutamate Receptor Antagonists, or by Inhibition of Nitric Oxide Synthase

\begin{tabular}{lcl}
\hline Experimental conditions & TUNEL-positive cells & Viable cells (per $\left.\mathrm{mm}^{3}\right)$ \\
\hline Control & $0.0 \pm 0.0$ & $14.5 \times 10^{4} \pm 0.2 \times 10^{4}$ \\
MD for 7 days & $8.0 \pm 0.3$ & $11.1 \times 10^{4} \pm 0.5 \times 10^{4 * *}$ \\
Optic nerve transection & $0.9 \pm 0.2^{*}$ & $\mathrm{ND}$ \\
MD for 7 days + L-NAME & $0.2 \pm 0.1^{*}$ & $13.6 \times 10^{4} \pm 0.7 \times 10^{4 * * *}$ \\
MD for 7 days + D-NAME & $8.1 \pm 0.3$ & $10.2 \times 10^{4} \pm 0.4 \times 10^{4 \$}$ \\
MD for 7 days + CGP040116 & $1.7 \pm 0.2^{*}$ & $14.5 \times 10^{4} \pm 0.8 \times 10^{4 * * *}$ \\
MD for 7 days + MK801 & $2.2 \pm 0.2^{*}$ & $13.6 \times 10^{4} \pm 0.6 \times 10^{4 * * *}$ \\
MD for 7 days + GYKI52466 & $0.8 \pm 0.1^{*}$ & $15.3 \times 10^{4} \pm 0.8 \times 10^{4 * * *}$ \\
\hline
\end{tabular}

Note MD was performed for 7 days in rats starting at 14 days of age. Untreated animals were used as controls. Different groups of MD animals were additionally treated with CGP040116 $\left(7 \mathrm{mg} \mathrm{kg}^{-1}\right)$, MK $801\left(0.3 \mathrm{mg} \mathrm{kg}^{-1}\right), \mathrm{GYK} 152466\left(3.3 \mathrm{mg} \mathrm{kg}^{-1}\right)$, with L-NAME $\left(3 \mathrm{mg} \mathrm{kg}{ }^{-1}\right.$, twice daily), with D-NAME ( $3 \mathrm{mg} \mathrm{kg}^{-1}$, twice daily), or by optic nerve transection (at the day of MD start). Adjacent brain tissue sections across the LGN were processed for in situ detection of DNA fragmentation (TUNEL technique) or stained with $H \& E$. The number of TUNEL-positive cells in the dLGN of either side of the brain and the number of viable cells per $\mathrm{mm}^{3}$ in the LGN contralateral to the deprived eye in identical animals ( $n=6$ per group) was scored as in Tables 1 and 2 . The results are expressed as mean \pm SEM. Data were evaluated statistically for differences using ANOVA followed by Tukey-Kramer multiple comparisons test. $* P<0.001$ vs. MD. ** P $<0.01$ vs control. *** $\mathrm{P}<0.01$ vs MD and $\mathrm{P}>0.05$ vs control; ${ }^{\$} \mathrm{P}<0.01$ vs control and $\mathrm{P}>0.05$ vs MD. ND, not determined.

\section{Glutamate Receptor Antagonists Prevent MD-Evoked Apoptosis in the dLGN}

Since the integrity of the retino-geniculate pathway was required for the occurrence of cell death in the dLGN after MD, we speculated that signals from the deprived eye are conveyed via the optic nerve to the contralateral LGN.

Therefore, we examined whether glutamatergic pathways were involved in the altered signaling to the dL GN after MD. Systemic administration of selective antagonists of the $\mathrm{N}$-methyl-D-aspartate receptor (NMDA-R) (e.g., MK801 and CGP040116) or nonNMDA glutamate receptor subtypes (e.g., GYKI 52466) protected against cell death observed in the LGN, 7 days after MD. Administration of MK $801\left(0.3 \mathrm{mg} \mathrm{kg}^{-1}\right.$ given i.p. once daily for 7 days during $M D ; n=6$ ) or CGP040116 ( $7 \mathrm{mg} \mathrm{kg}^{-1}$ given i.p. once daily for 7 days during MD; $n=6$ ) reduced the number of TUNEL positive cells by 73 and $79 \%$, respectively (Table 3 ); lower doses were ineffective (data not shown). Administration of GYKI 52466 (3.3 $\mathrm{mg} \mathrm{kg}^{-1}$ given i.p. once per day for 7 days during MD; $n=6$ ) reduced the number of TUNEL positive cells by $91 \%$ (Table 3). Furthermore, treatment with MK801, CGP040116 or GYKI52466 (same treatment as above) prevented the loss of viable cells elicited by 7 days of MD (Table 3).

\section{Monocular Deprivation Activates Nitric Oxide \\ Synthase in the dLGN}

Stimulation of ionotropic glutamate receptors can cause activation of the neuronal nitric oxide synthase (NOS). To investigate NOS activity in the dLGN, we measured the content of citrulline, the coproduct of NO synthesis, at different times after MD. Citrulline levels increased significantly in newborn rats after one day of MD. This increase was transient, since its levels were again similar to those of age-matched nondeprived controls, after 7 days of MD (Table 4). The increase in citrulline levels observed after 1 day of MD was abolished by treatment with either the NMDA-R antagonist MK801, or the non-NMDA-R antagonist GYKI52466 (Table 4). Prevention of augmented citrulline by the NOS inhibitor, L-NAME, but not by D-NAME, the less active isomer (4) confirmed that MD stimulates NOS.

\section{TABLE 4}

Effect of Monocular Deprivation (MD) on the Citrulline Content of the Lateral Geniculate Nucleus (LGN)

\begin{tabular}{lll}
\hline \multirow{2}{*}{ Treatment } & \multicolumn{2}{c}{ Analysis at } \\
\cline { 2 - 3 } & \multicolumn{1}{c}{$24 \mathrm{~h}$} & 7 days \\
\hline Control & $132 \pm 6$ & $178 \pm 11$ \\
MD & $182 \pm 7^{*}$ & $177 \pm 10$ \\
MD + MK801 & $136 \pm 8^{* *}$ & \\
MD + GYKI52466 & $139 \pm 11^{* *}$ & \\
MD + L-NAME & $151 \pm 4^{* * *}$ & \\
MD + D-NAME & $179 \pm 5^{\S}$ & \\
\hline
\end{tabular}

Note HPLC measurement of citrulline was performed in homoge nates of LGN enriched tissue obtained from newborn rats $24 \mathrm{~h}$ and 7 days after the start of MD, and from age-matched control rats. Animals were treated during MD with MK801 $\left(0.3 \mathrm{mg} \mathrm{kg}^{-1}\right)$, GYKI52466 (3.3 mg kg ${ }^{-1}$ ), L-NAME (3 $\mathrm{mg} \mathrm{kg}^{-1}$, twice daily), or with D-NAME (3 mg kg-1, twice daily) or were left without further treatment. Data are expressed as nmol of citrulline/g of wet tissue weight. Data are expressed as mean \pm SEM of 6 animals per group. Statistical differences were evaluated using ANOVA followed by TukeyKramer multiple comparisons test. * $\mathrm{P}<0.001$ vs. control; $* * \mathrm{P}<$ 0.001 vs $\mathrm{MD} ;{ }^{* * *} \mathrm{P}<0.005$ vs $\mathrm{MD} ;{ }^{\S} \mathrm{P}>0.05$ vs MD. 
TABLE 5

PARP -/- Mice Are Resistant to Apoptosis Typically Induced by Monocular Deprivation in the d LGN

\begin{tabular}{lll}
\hline & Wild-type & PARP $-/-$ \\
\hline Control & $0.0 \pm 0.0$ & $0.0 \pm 0.0$ \\
MD for $48 \mathrm{~h}$ & $2.7 \pm 0.2$ & $0.9 \pm 0.2^{*}$ \\
MD for 7 days & $3.5 \pm 0.3$ & $0.3 \pm 1.2^{* *}$ \\
\hline
\end{tabular}

Note. MD was induced in wild-type or PARP -/- mice at 14 days postpartum. After 2 or 7 days of MD, brains were removed and processed for detection of TUNEL positive cells in the LGN. Cells were scored in the LGN contralateral to the deprived eye and the data are expressed as means \pm SEM from 6 animals per group. Statistical comparison between the two genotypes of corresponding groups of treatment was performed by Student's t test. * $\mathrm{P}<0.01$ vs wild-type; $* * ~ P<0.05$ vs wild-type.

\section{Requirement of NOS Activation and PARP \\ in the Apoptosis Triggered by MD}

We went on testing whether NOS activation was involved in the mechanisms of cell death after MD. Administration of L-NAME, but not D-NAME prevented cell death (Table 3 ) and neuronal loss in the dLGN (Table 3). Notably, it has been proposed that activation of PARP is a key mechanism for glutamate and NO toxicity (16). To investigate PARP involvement in MD-triggered cell death, we decided to use mice lacking the PARP gene (PARP -/-) (5). I nitial experiments, showed that MD in mice, caused cell death in the LGN with morphological features virtually indistinguishable from those observed in rats. Then, both wt and PARP $-/-$ mice were treated as described for rats, and cell death in the dLGN was scored. As shown in Table 5, cell death was reduced in a statistically significant fashion in PARP $(-/-)$ mice as compared to wild-type.

\section{DISCUSSION}

The present experiments show that monocular deprivation for 2,7 , and 14 days produces in situ DNA fragmentation, nuclear chromatin marginalization and condensation in the dLGN of newborn rats, suggesting the occurrence of apoptotic cell death. The latter interpretation is supported by the observation made in adjacent tissue sections of increased expression of p53, a tumor suppressor gene whose activation has been associated with the occurrence of apoptosis in DNA damaged cells (13). Interestingly, cell death was accompanied by a progressive dedine in the number of viable cells counted in the dLGN of rats deprived for 2,7 , or 14 consecutive days, suggesting that elimination of cells by apoptosis may account, at least in part, for the cell loss. The presence of TUNEL-positive cells and the occurrence of cell loss were more evident in the dLGN contralateral to the deprived eye. A more limited number of TUNEL-positive cells was detected in the dLGN ipsilateral to the deprived eye and this was associated with a change in the number of viable cells which was not statistically significant. These findings are consistent with previous data indicating that in rats more than $95 \%$ of the optic nerve fibres cross at the level of the optic chiasm and terminate in the contralateral dLGN (17). Possibly, input signals originating from the deprived eye are transmitted through the optic nerve fibers mainly to the contralateral dLGN. This concept is supported by the observation that transection of the optic nerve of the deprived eye abolishes cell death and loss in the contralateral dLGN. Under the present experimental conditions, MD failed to damage the retina and this is at variance with the dramatic changes seen in the retina (18) but not in the dLGN (present data) caused by optic nerve transection, further supporting the requirement of an intact optic nerve for cell death to occur in the dLGN of MD rats.

Previous studies have documented that NMDA receptors play a role in the refinement of the visual pathway during development, and in the mechanisms of ocular dominance plasticity during $\operatorname{MD}(19,20)$. More recent data obtained in kittens demonstrate that monocular deprivation for $48 \mathrm{~h}$ leaves sufficient residual activity in the deprived retina to induce homosynaptic long-term depression (21). This mechanism of synaptic plasticity typically utilises glutamate in mammalian brain (22). Here, we observed that both NMDA and non-NMDA glutamate receptor antagonists protected rats from MD-evoked cell death and loss in the dLGN. Thus, glutamatergic stimulation seems to be essential for cell death triggered by MD. This may either involve glutamate and its receptors as a relay for secondary cytotoxic signals, or direct cytotoxicity by glutamate. At least two different mechanisms may be responsible for glutamate toxicity. Overstimulation of glutamatergic receptors can trigger excitotoxic cell death in cultured neuronal cells $(23,24)$, most likely by increasing the influx of extracellular ions such as $\mathrm{Na}^{+}$, $\mathrm{Ca}^{2+}$, and $\mathrm{Zn}^{2+}$. Damage from ion overload can proceed independently of NO synthesis. In addition, excessive exposure of some neuronal subsets to glutamate activates the $\mathrm{Ca}^{2+}$-dependent $\mathrm{NOS}$ and formation of $\mathrm{NO}$ / ONOO. NOS containing neurons are generally more resistant to direct NO toxicity, and to the related downstream mechanisms (i.e., PARP activation) (25-27). Nevertheless, the NO they generate may be involved in killing of other neuronal subsets, which may be more sensitive to NO- or radical-mediated lethal processes. Accordingly, experiments using inhibitors of NOS and studies performed in gene-targeted mice which lack different isoforms of NOS suggest that NO production in a small number of neurons is involved as downstream mediator in various neuropathological processes $(28-31)$. A role for NOS in neuronal cell death 

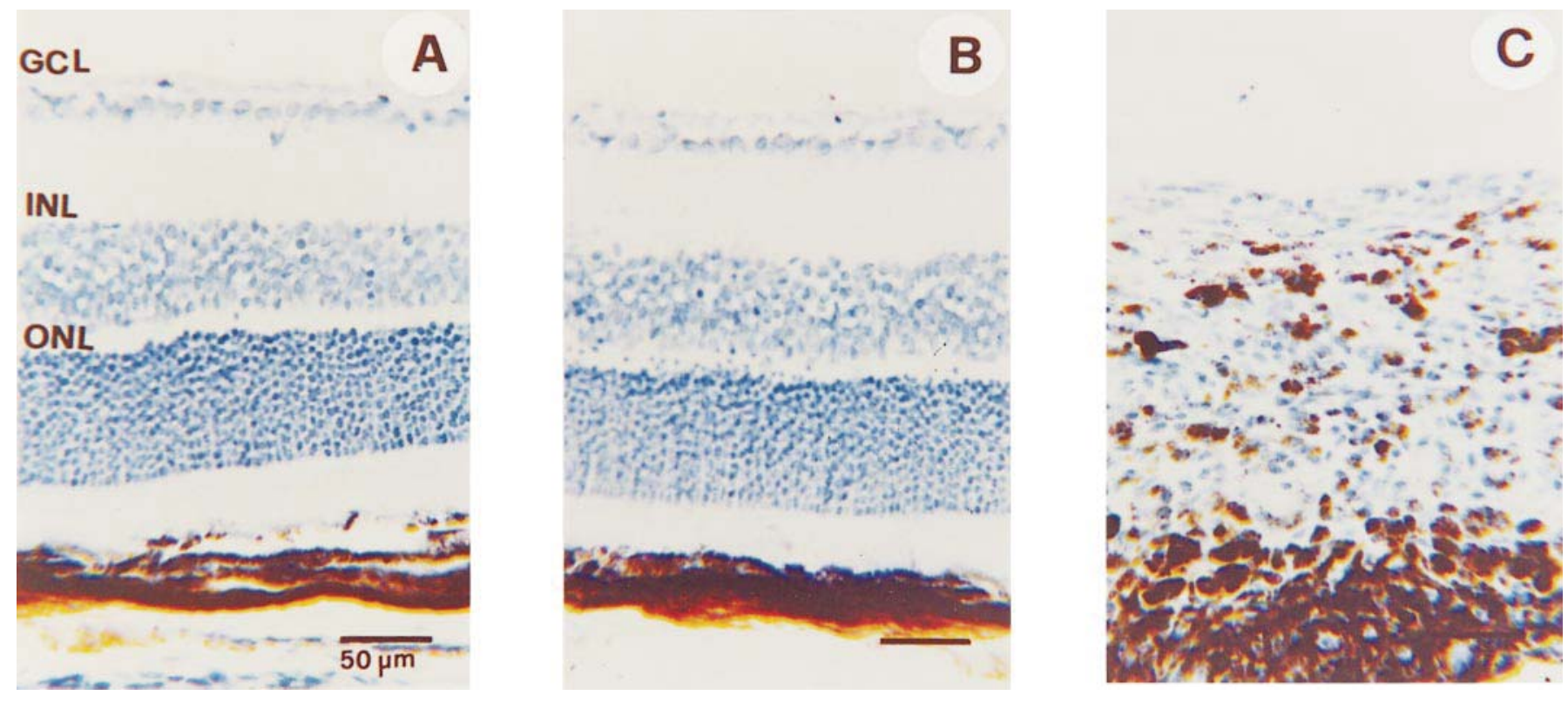

FIG. 3. DNA fragmentation in the retina of newborn rats induced by optic nerve transection but not monocular deprivation. No in situ DNA fragmentation (TUNEL-positive cells) was detected in the retina of a control newborn rat (A) or in the retina after 7 days of MD (B). TUNEL-positive cells, dispersed throughout the whole thickness of the tissue, and dramatic alteration of the architecture were observed in retinas 7 days after optic nerve transection (C). GCL, ganglion cell layer; INL, inner nuclear layer; ONL, outer nuclear layer.

triggered by MD is supported by the significant increase in the concentrations of citrulline, the coproduct of NO synthesis (32), in the deprived LGN. Citrulline concentrations were increased al ready $24 \mathrm{~h}$ after $M D$, whereas cell death was not observed at that time point. Thus, it seems conceivable that increased NOS activity was involved in the mechanisms which trigger cell death. The causal involvement was then confirmed by the stereoselective inhibition of cell loss by the NOS inhibitor L-NAME.

Finally, our experiments in PARP-deficient mice suggest that downstream to NO production, PARP may be involved in the progression of cell death in this system. The importance of PARP has been demonstrated in several models where cell death is essentially linked to NO production, such as neuronal death in stroke (31), in excitotoxin-exposed cortical neurons (33), in the substantia nigra of MPP exposed animals (34). In contrast, PARP seems to play no role in excitotoxic neuronal apoptosis in cerebellar granule neurons, which contain high NOS levels and are resistant to direct NO effects $(25,35)$.

Based on these findings, the most likely sequence of events triggered by MD involves glutamatergic signals, which lead to NOS activation with increased NO production, activation of PARP, apoptosis and cell loss. While this chain of events has been invoked to explain acute neurodegeneration, here we show that glutamatergic stimulation can underlay apoptosis and loss of neurons in slow progressing degenerative conditions.

\section{ACKNOWLEDGMENTS}

Financial support from the National Council for Research (to G.B.) and the Deutsche Forschungsgemeinschaft (Projects Ni 519/1-1 and $2-1$ ) is gratefully acknowledged. Special thanks go to Dr. M. G. Treccozzi, Dr. M. Lombardo, Dr. A. Froiio, Mr. C. Del Duca, Ms. Heike Naumann, and Mr. N. Fico for excellent technical assistance.

\section{REFERENCES}

1. Wiesel, T. N., and Hubel, D. H. (1963) Effects of visual deprivation on morphology and physiology of cells in the cat's lateral geniculate body. J . Neurophysiol. 26, 1003-1017.

2. Sherman, S. M., and Spear, P. D. (1982) Organization of the visual pathways in the normal and visually deprived cats. Physiol. Rev. 62, 738-855.

3. Rauschecker, J . F. (1991) Mechanisms of visual plasticity: Hebb synapses, NMDA receptors, and beyond. Physiol. Rev. 71, 587615.

4. Knowles, R. G., and Moncada, S. (1994) Nitric oxide synthases in mammals. Biochem. J . 298, 249-258.

5. Wang, Z.-Q., Auer, B., Stingl, L., Berghammer, H., Haidacher, D., Scweiger, M., and Wagner, E. F. (1995) Mice lacking ADPRT and poly(ADP-ribosyl)ation develop normally but are susceptible to skin disease. Genes Dev. 9, 509-520.

6. Mesulam, M. M. (1982) in Tracing Neural Connections with Horseradish Peroxidase, pp. 1-152. Wiley, UK.

7. Gavrieli, Y., Sherman, Y., and Ben-Sasson, S. A. (1992) Identification of programmed cell death in situ via specific labeling of nuclear DNA fragmentation. J . Cell Biol. 119, 493-501.

8. West, M. J . (1993) New stereological methods for counting neurons. Neurobiol. Aging 14, 275-285.

9. Bagetta, G., Corasaniti, M. T., Berliocchi, L., Nisticò, R., Giammarioli, A. M., Malorni, W., Aloe, L., and Finazzi-Agrò, A. (1999) 
Involvement of interleukin-1b in the mechanism of human immunodeficiency virus type 1 (HIV-1) recombinant protein gp120induced apoptosis in the neocortex of rat. Neuroscience 89, 10511066.

10. Mansour-Robaey, S., Clarke, D. B., Wang, Y. C., Bray, G. M., and Aguayo, A. J . (1994) Effects of ocular injury and administration of brain-derived neurotrophic factor on survival and regrowth of axotomized retinal ganglion cells. Proc. Natl. Acad. Sci. USA 91, 1632-1636.

11. Bagetta, G., Rodinò, P., Paoletti, A. M., Arabia, A., Massoud, R., and Nisticò, G. (1995) Systemic administration of lithium and tacrine but not kainic acid augments citrulline content in the brain of rat. Eur. J . Pharmacol. 294, 341-344.

12. Kerr, J . F. R., Searle, J ., Harmon, B. V., and Bishop, C. J . (1987) in Prospective on Mammalian Cell Death (Potten, C. S., Ed.), pp. 93-128. Oxford Univ. Press, Oxford, UK.

13. Clarke, A. R., Purdie, C. A., Harrison, D. J ., Morris, R. G., Bird, C. C., Hooper, M. L., and Wyllie, A. H. (1993) Thymocyte apoptosis induced by p53-dependent and independent pathways. Nature 362, 849- 852

14. Eng, L. F., and Ghirnikar, R. S. (1994) GFAP and astrogliosis. Brain Pathol. 4, 229-237.

15. Ling, E. A., and Wong, W. C. (1993) The origin and nature of ramified and amoeboid microglia: A historical review and current concepts. Glia 7, 9-18.

16. Dawson, V. L., and Dawson, T. M. (1996) Nitric oxide actions in neurochemistry. Neurochem. Int. 29, 97-110.

17. Lund, R. D. (1965) Uncrossed visual pathway of hooded and al bino rats. Science 149, 1506-1507.

18. Villegas-Perez, M. P., Vidal-Sanz, M., Rasminsky, M., Bray, G. M., and Aguaio, A. J . (1993) Rapid and protracted phase of retinal ganglion cell loss follow axotomy in the optic nerve of the adult rats. J. Neurobiol. 24, 23-36.

19. Kleinschmidt, A., Bear, M. F., and Singer, W. (1989) Blockade of NMDA receptors disrupts experience dependent plasticity of kitten striate cortex. Science 238, 355-358.

20. Hahm, J . O., Langdon, R. B., and Sur, M. (1991) Disruption of retinogeniculate afferent segregation by antagonists to NMDA receptors. Nature 351, 568-570.

21. Rittenhouse, C. D., Shouval, H. Z., Paeadiso, M. A., and Bear, M. F . (1999) Monocular deprivation induces homosynaptic longterm depression in visual cortex. Nature 397, 347-350.

22. Dudek, S. M., and Bear, M. F. (1992) Homosynaptic long-term depression modification in area CA1 of hippocampus and the effects of NMDA receptor blockade. Proc. Natl. Acad. Sci. USA 89, 4363- 4367.
23. Ankarcrona, M., Dypbukt, J. M., Bonfoco, E., Zhivotovsky, B., Orrenius, S., Lipton, S. A., and Nicotera, P. (1995) Glutamateinduced neuronal death: A succession of necrosis or apoptosis depending on mitochondrial function. Neuron 15, 961-973.

24. Bonfoco, E., Krainc, D., Ankarcrona, M., Nicotera, P., and Lipton, S. A. (1995) Apoptosis and necrosis: Two distinct events induced respectively by mild and intense insults with NMDA or nitric oxide/superoxide in cortical cell cultures. Proc. Natl. Acad. Sci. USA 92, 7162-7166.

25. Leist, M., Volbracht, C., Kuhnle, S., Fava, E., Ferrando-May, E., and Nicotera, P. (1997a) Caspase-mediated apoptosis in neuronal excitotoxicity triggered by nitric oxide. Mol. Med. 3, 750764.

26. Leist, M., and Nicotera, P. (1998) Apoptosis, excitotoxicity and neuropathology. Exp. Cell. Res. 239, 183-201.

27. Snyder, S. H., J affrey, S. R., and Zakhary, R. (1998) Nitric oxide and carbon monoxide: Parallel roles as neural messengers. Brain Res. Rev. 26, 167-175.

28. Schulz, J . B., Huang, P. L., Matthews, R. T., Passov, D., Fishman, M. C., and Beal, M. F. (1996) Striatal malonate lesions are attenuated in neuronal nitric oxide synthase knockout mice. J . Neurochem. 67, 430- 433.

29. Snyder, S. H. (1996) No NO prevents parkinsonism. NatureMed. 2, 965-966.

30. Galpern, W. R., Matthews, R. T., Beal, F. M., and Isacson, O. (1996) NGF attenuates 3-nitrotyrosine formation in a 3-NP model of Huntington's disease. NeuroReport 7, 2639-2642.

31. Samdani, A. F., Dawson, T. M., and Dawson, V. L. (1997) Nitric oxide synthase in models of focal ischemia. Stroke 28, 12831288.

32. Moncada, S., Palmer, R. M. J ., and Higgs, A. (1993) Nitric oxide: Physiology, pathophysiology and pharmacology. Pharmacol. Rev. 43, 109-142.

33. Dawson, V. L., Kizushi, V. H., Huang, P. L., Snyder, S. H., and Dawson, T. M. (1996) Resistance to neurotoxicity in cortical cultures from neuronal nitric oxide synthase-deficient mice. J . Neurosci. 96, 2479-2487.

34. Matthews, R. T., Beal, M. F., Fallon, J ., Fedorchak, K., Huang, P. L., Fishman, M. C., and Hyman, B. T. (1997) MPP+ induced substantia nigra degeneration is attenuated in nNOS knockout mice. Neurobiol. Dis. 4, 114-121.

35. Leist, M., Suìngle, B., Kunstle, G., Volbracht, C., Hentze, H., and Nicotera, P. (1997) Apoptosis in the absence of poly-(ADPribose) polymerase. Biochem. Biophys. Res. Commun. 233, 518522. 